\title{
Turismo Cultural e Desenvolvimento Includente: o caso de Paranaguá, Paraná, Brasil
}

\section{Cultural Tourism and Includent Development: the case of Paranaguá, Parana, Brazil}

\author{
Cinthia Sena Abrahão ${ }^{1}$ \\ Miguel Bahl ${ }^{2}$
}

\section{Resumo}

O artigo tem por objetivos discutir o potencial do turismo cultural para o desenvolvimento das cidades, considerando a perspectiva da inclusão e da sustentabilidade, bem como realizar reflexão sobre o caso da cidade de Paranaguá, no estado do Paraná (Brasil). A metodologia utilizada para o estudo foi baseada na revisão bibliográfica, associada à pesquisa iconográfica e à análise de documentos históricos. Em termos de resultados, pode-se apontar o potencial efetivo para o desenvolvimento do turismo cultural em Paranaguá, tendo em vista seu patrimônio histórico e culturalmente preservado.

Palavras-chave: turismo cultural; patrimônio material; desenvolvimento includente; Paranaguá (Brasil).

\section{Abstract}

The article aim for discuss the potential of the cultural tourism for the development of the cities, considering the perspective of the inclusion and of the sustentability, as well as to carry out reflection on the case of the city of Paranagua, in the state of the Parana (Brazil). The methodology used for the study was based on the bibliographical revision associated to the inquiry iconographic and historical analysis of documents. In terms of results, it is possible to point to the effective potential for the development of the cultural tourism in Paranagua, based on historical and culturally preserved inheritance.

Keywords: cultural tourism; material inheritance; includent development; Paranaguá (Brazil).

\footnotetext{
1 Bacharel em Economia pela Universidade Federal de Uberlândia, Mestre em História Econômica pela Universidade de São Paulo (USP) e doutoranda em Geografia pela Universidade Federal do Paraná (UFPR). Professora do curso de Gestão em Turismo e Gestão e Empreendedorismo (UFPR - Campus Litoral). Email: cisena@terra.com.br.

${ }^{2}$ Bacharel em Turismo e Licenciado em Estudos Sociais e em Geografia pela Universidade Federal do Paraná (UFPR). Mestre e Doutor em Ciências da Comunicação (Turismo e Lazer) pela Universidade de São Paulo (USP). Professor do Curso de Graduação em Turismo e do Programa de Mestrado e Doutorado em Geografia (UFPR). Email: migbahl@ufpr.br.
} 


\section{Introdução}

O turismo de base cultural tem se apresentado de forma cada vez mais destacada como uma alternativa para diversas cidades que possuem atrativos monumentais, artísticos, bem como de costumes e práticas sociais tidas como tradicionais. Isso permite afirmar que economia e cultura podem se entrelaçar na busca de novas alternativas de desenvolvimento ${ }^{3}$ das cidades. Fita (2003, p. 83) demonstra como a cidade de Barcelona foi beneficiada, ao longo de uma trajetória centenária, por uma infra-estrutura que viabilizou implementar políticas culturais com vistas ao seu desenvolvimento urbano e social e que acabou também beneficiando o desenvolvimento do turismo.

Ao pesquisar sobre a cidade de Paranaguá e sua formação territorial identifica-se que a especialização na atividade portuária obstruiu ao longo do tempo a valorização da sua riqueza patrimonial e cultural expressa na configuração espacial, que se traduz em potencial turístico. A dependência econômica construída em função da atividade portuária, por sua vez, trouxe uma série de impactos ambientais e sociais que marcam a cidade.

A riqueza produzida pela atividade portuária, no entanto, não é incorporada de forma plena pelos moradores da cidade. Desta forma, pode-se dizer que existe uma relação contraditória fundamental entre porto e cidade, na medida em que todos os impactos depreciativos ficam retidos no espaço territorial da cidade, enquanto os positivos, em termos de geração de renda e emprego, o são apenas parcialmente.

Martinelli (2003, p. 93), em sua reflexão sobre as "políticas culturais territoriais locais" na Espanha mostra como a experiência da segunda metade do século XX foi capaz de evidenciar que não é possível produzir desenvolvimento, na perspectiva da garantia e expansão do bemestar da população, se a perspectiva cultural for subjugada. "As políticas culturais locais [podem] fomentar a recuperação das identidades culturais locais e territoriais. É preciso desenvolver em cada população a auto-estima, a valorização daquilo de que dispõem em termos de cultura" (MARTINELLI, 2003, p. 96).

A conjuntura política, econômica, bem como os marcos legais contemporâneos, possibilitam rever as configurações das cidades e dar visibilidade aos seus potenciais turísticos, apontando

\footnotetext{
${ }^{3}$ Na perspectiva de Ignacy Sachs (2004), o termo desenvolvimento passa a requerer a capacidade de gerar e distribuir riquezas, assumindo o caráter da inclusão da população.
} 
para novas perspectivas em termos de prospecção do desenvolvimento. Transformá-los em fundamento para o desenvolvimento com foco na inclusão social da população residente nestas cidades e no que as circunda, representa um desafio considerável. As experiências de desenvolvimento baseadas no potencial cultural, especialmente no turismo cultural, demonstram capacidade de estimular o surgimento de empreendimentos e empregos criativos, que possibilitam aos jovens trabalhar sob novas condições.

O objetivo deste artigo é refletir sobre o potencial turístico cultural do município de Paranaguá, litoral do Paraná (Brasil), cujo processo de ocupação e constituição citadina remonta ao século XVII. Acredita-se que tal discussão possa subsidiar a problematização da proposição de um turismo sustentável e includente presente nas políticas públicas atuais. Deve-se ressaltar que a cidade de Paranaguá contemporaneamente passa a ser contemplada por políticas federais calcadas nesta perspectiva.

A pesquisa teórica que subsidiou a análise para a elaboração deste trabalho se baseou em um processo de revisão bibliográfica, bem como na análise documental, tendo sido organizada textualmente em quatro tópicos. No primeiro tópico, destaca-se o patrimônio histórico da cidade de Paranaguá, buscando revelar os testemunhos que nele estão contidos; o segundo remete ao potencial para o turismo cultural, bem como os diferenciais que esta modalidade da atividade turística pode propiciar, no sentido do desenvolvimento da cidade; no terceiro tópico faz-se um destaque para a Ilha do Mel, como atrativo consolidado do município, buscando articulá-la ao contexto mais geral da cidade; e, por fim, faz-se uma alusão às possibilidades que se abrem com a escolha de Paranaguá como um dos 65 destinos turísticos indutores do desenvolvimento no Brasil, a partir do Plano Nacional de Turismo - 2007/2010 (BRASIL, 2006).

Em termos de apontamentos finais, buscou-se discutir a urgência e relevância do planejamento para que a atividade turística possa de fato vir a contribuir para o desenvolvimento da cidade. Desta forma, subsidia-se a geração de novas perspectivas para a solução dos inúmeros problemas sócio-econômicos e ambientais que são vivenciados no contexto da cidade de Paranaguá. 


\section{Paranaguá: o patrimônio como testemunha da história}

Segundo Silva (s/d), o conceito clássico de patrimônio, sob o qual ficam englobadas as heranças do passado que são transmitidas às gerações futuras, expressa a consolidação das manifestações culturais humanas. E mais, representam na verdade, um conjunto de escolhas realizadas por um grupo de indivíduos. Constituem uma expressão espaço-temporal de valores culturais selecionados por grupos humanos. Através destas escolhas, portanto, podemse construir identidades, dar sentido de existência e de pertencimento.

Conforme Meneses (2004), o patrimônio representa uma herança viva, que não se reduz a uma peça expositiva, ao conjunto das lembranças curiosas. Construções culturais expressam, por assim dizer, um edificado de significações, estejam elas materializadas no espaço ou apresentem caráter subjetivo.

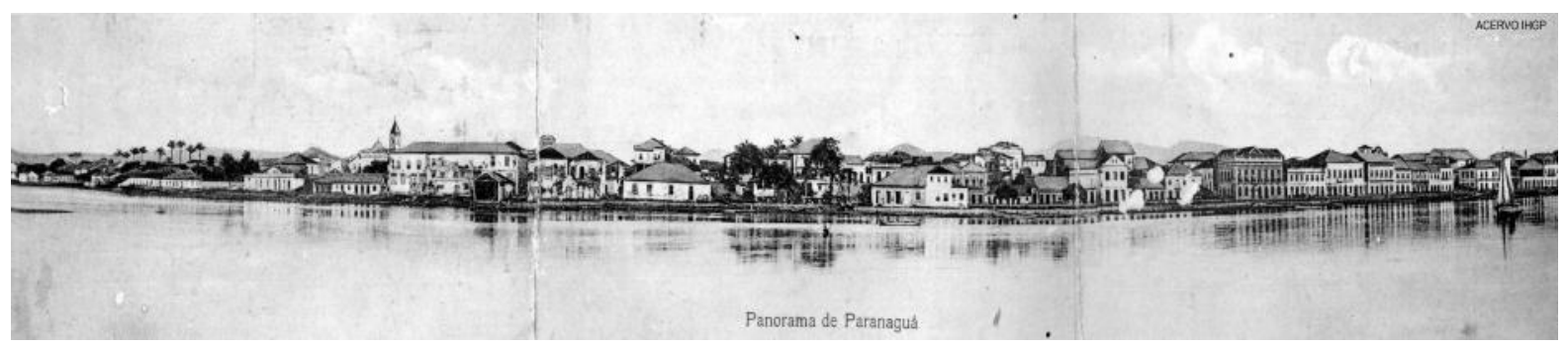

Figura 1 - Foto: Paranaguá histórica. Autor desconhecido. S/d.

Fonte: Acervo do Instituto Históricogeográfico de Paranaguá

A cidade de Paranaguá fica situada defronte da extremidade ocidental da Ilha da Cotinga, a algumas centenas de passos da Foz de um pequeno rio denominado Rio de Paranaguá e um pouco acima dele.

Quando se chega a Paranaguá, vindo do interior, onde a maioria das casas das vilas e arraiais são feitas de barro, o que chama a nossa atenção é ver todas as casas e todos os prédios públicos feitos de pedra.

A cidade se compõe de algumas ruas que se estendem paralelamente ao rio e são cortadas por outras de pequena extensão. As primeiras são geralmente largas e bem alinhadas; ninguém se deu ao trabalho de pavimentá-las, e no entanto elas jamais se mostram barrentas, já que o terreno ali é muito arenoso.

De um modo geral elas parecem bem cuidadas, mas quase todas têm apenas um pavimento. 
A cidade conta com três igrejas, a paroquial e mais outras duas de menor importância. A primeira, dedicada a Nossa Senhora do Rosário, é mais ampla do que a maioria das que eu já tinha visto no Brasil. (SAINTHILAIRE, 1978, p. 99).

O relato do viajante naturalista Auguste Saint-Hilaire, que visitou o Brasil no início do século XIX traduz as impressões obtidas em sua passagem na década de 1820 pelas províncias do sul do Brasil, quando esteve no litoral do Paraná. Merece destaque o fato de que a descrição é reveladora das marcas arquitetônicas de uma vila importante, no período em questão. Contemporaneamente, a parcela preservada destas marcas traduz um fragmento do patrimônio cultural da cidade.

O conjunto arquitetônico da cidade passa a representar o elo espaço-tempo, um contraponto à lógica moderna que impõe a mudança permanente. A relação de estranhamento passa a compor o ambiente, na medida em que a lógica dialética de imposição do modelo de mudança permanente teima em desconstruir a identificação com o passado que perpetua a tradição (SILVA, s/d).

Embora o primeiro núcleo urbano de Paranaguá tenha sido organizado no século XVI em função da exploração aurífera (LICCARDO et al., 2004), não há registros que sustentem sua importância econômica ao longo dos séculos seguintes, até o momento do relato de SaintHilaire. A exploração de ouro foi efêmera e incapaz de justificar uma atenção efetiva da administração colonial, e da mesma forma as atividades que a sucederam. Então, o que teria justificado que chegasse ao primeiro quartel do século XIX com marcas espaciais tão bem estruturadas e imponentes, a ponto de impressionar um viajante, que havia visitado as cidades mineiras, portadoras da herança do ciclo minerador do século XVIII?

O peso do Brasil na sustentação do império lusitano setecentista, associado à ascensão de Sebastião José de Carvalho e Melo, o Marquês de Pombal, ao cargo de Primeiro Ministro do reinado de Dom José I, constituíram elementos essenciais para as políticas territoriais executadas ao longo dos 27 anos em que dirigiu o império (COUTO, 2003). A posição geográfica estratégica de Paranaguá, por sua vez, possibilitou que se constituísse como um dos núcleos urbanos beneficiados pelas políticas pombalinas de ocupação e defesa dos territórios de fronteira. 
Neste sentido, pode-se dizer que as marcas espaciais da cidade de Paranaguá ainda preservam parte relevante da história do Brasil. Na aparência, esta herança está expressa nos monumentos e na arquitetura, na essência reflete o processo histórico através da etnia, dos costumes e na própria organização política contemporaneamente. Estes elementos associados, revelados em sua profundidade, podem contribuir para um direcionamento turístico, em especial para o turismo cultural. A perspectiva cultural, por sua vez, vista com esta amplitude, remete ao planejamento tendo em vista a construção de políticas voltadas para o desenvolvimento includente.

Vale destacar que no presente artigo adota-se como motriz a definição estabelecida pelo Ministério do Turismo do Brasil:

Turismo Cultural compreende as atividades turísticas relacionadas à vivência do conjunto de elementos significativos do patrimônio histórico e cultural e dos eventos culturais, valorizando e promovendo os bens materiais e imateriais da cultura. (BRASIL, 2008, p. 16).

Torna-se oportuno esclarecer que tal definição foi elaborada em parceria com o Ministério da Cultura e o Instituto do Patrimônio Histórico Nacional - IPHAN e com base na representatividade da Câmara Temática de Segmentação do Conselho Nacional de Turismo.

Conforme Taddei Neto (2003, p. 107) até 2003, dos 600 núcleos urbanos históricos no Brasil, pouco mais de 100 tinham sido colocados sob alguma forma de proteção patrimonial. É fato que a maior e a mais significativa parte do patrimônio histórico nacional que se tornou objeto de proteção está situada em áreas que de alguma maneira fícaram ao largo do desenvolvimento econômico, sobretudo aquele pautado no modelo industrial. Por outro lado, ainda é incipiente o planejamento e o investimento no turismo cultural, pensado como uma alternativa sustentável para o desenvolvimento dos lugares que possuem a herança patrimonial e artística como atrativos relevantes.

De acordo com a análise presente no documento de tombamento do centro histórico de Paranaguá realizada em 1990 pela Coordenadoria de Cultura do Estado do Paraná, e 
reconhecida contemporaneamente pelo $\mathrm{IPHAN}^{4}$, o conjunto urbano edificado nos séculos XVIII e XIX permanece perfeitamente identificável (PARANÁ, 1990).

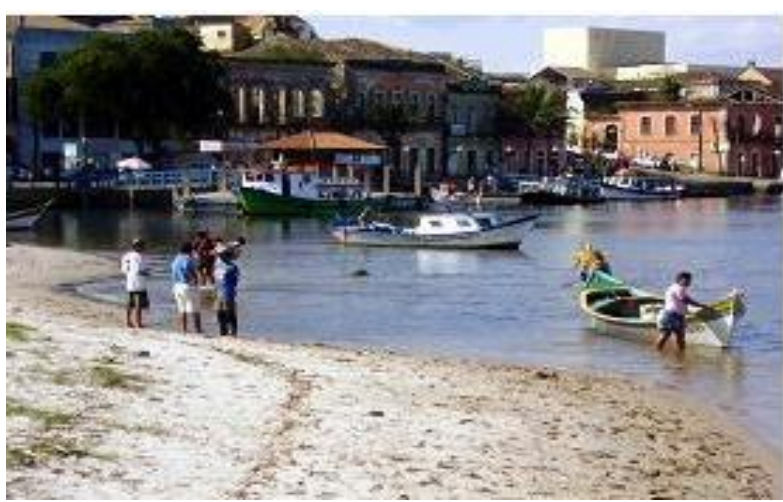

Figura 2 - Foto: pescadores na prainha

Fonte: Incubadora Tecnológica de Cooperativas Populares. UFPR Litoral. Projeto Villa, 2008.

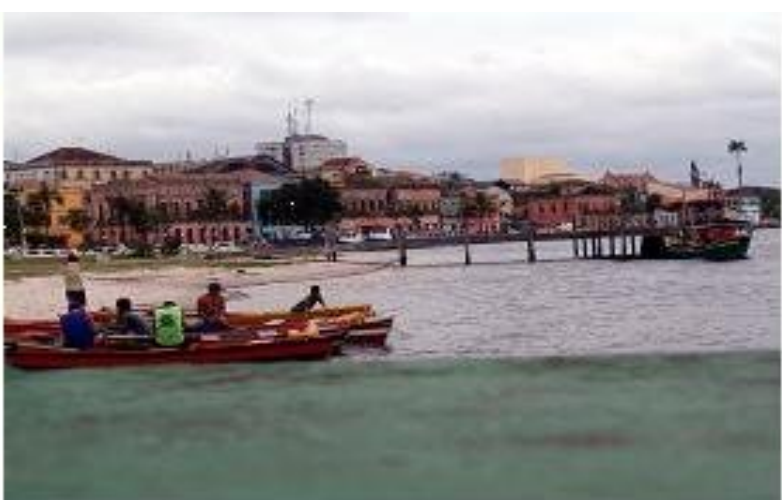

Figura 3 - Foto: centro histórico

Fonte: Incubadora Tecnológica de Cooperativas Populares. UFPR Litoral. Projeto Vila, 2008.

A parte antiga da cidade ou cidade histórica, que se estende à margem do rio Itiberê possui paisagem própria. Formada por uma trama de ruas e vielas tortuosas, de onde se destacam edificações capazes de testemunhar os traços do passado e de sua pretérita importância. Mas se esta "sobreviveu quase incólume em termos de escala urbana, no que diz respeito aos elementos arquitetônicos restou fracionada em conjuntos e monumentos ainda portadores de suas características primitivas" (PARANÁ, 2006).

[...] o patrimônio define menos o que se possui, o que se tem e se circunscreve mais ao que somos, sem sabê-lo, ou mesmo sem ter podido saber. O patrimônio se apresenta então como um convite à anamnese coletiva. Ao "dever" da memória, com a sua recente tradução pública, o remorso, se teria acrescentado alguma coisa como a "ardente obrigação" do patrimônio, com suas exigências de conservação, de reabilitação e de comemoração (HARTOG, 2006, p. 266).

\footnotetext{
${ }^{4}$ É recente o tombamento do núcleo histórico de Paranaguá como patrimônio histórico nacional, realizado em 2009.
} 
Segundo Losekam (2009a) o centro histórico de Paranaguá, tombado desde a década de 1990 pelo patrimônio estadual, foi também reconhecido como patrimônio histórico nacional em dezembro de 2009. O autor também comenta que a análise do Instituto de Patrimônio Histórico e Artístico Nacional (IPHAN) destaca a relação entre a estrutura das construções e a organização da economia local entre o final do século XVI até 1896. Ainda segundo Losekam (2009a), a cidade portuária de Paranaguá recebeu:

[...] influências do neoclassicismo, em razão do contato com o Rio de Janeiro e outros países. Características do movimento estão em construções como a Câmara Municipal, o Palacete Visconde de Nácar e o prédio comercial da Rua XV de Novembro (Casas Jaraguá), com fachada de azulejos e emolduramento de vãos em cantaria.

Tal reconhecimento permite contemplar inicialmente $\mathrm{o}$ conjunto arquitetônico $\mathrm{e}$ de imaginárias (Quadro 01) que permaneceram praticamente inalterados em função especialmente do processo de tombamento estadual. Além disso, houve a ratificação deste patrimônio reconhecido anteriormente no plano diretor de Paranaguá aprovado em 1967, que buscava ordenar o crescimento da cidade, preservando sua memória (PARANÁ, Dez/90). Em que pese esta iniciativa definitivamente importante, o conjunto patrimonial imaterial não foi contemplado.

Quadro 1 - Relação dos Bens Tombados pelo Patrimônio Estadual

\begin{tabular}{|l|l|}
\hline \multicolumn{1}{|c|}{ BENS TOMBADOS } & \multicolumn{1}{c|}{ DESCRITIVO } \\
\hline Antiga Alfândega de Paranaguá & $\begin{array}{l}\text { Prédio construído entre o fim do século XIX e início do } \\
\text { século XX, arquitetura eclética, predominantemente do } \\
\text { estilo Romano-Renascentista. }\end{array}$ \\
\hline Antigo Colégio dos Jesuítas & $\begin{array}{l}\text { Construído em meados do século XVII (1740/1750) segue o } \\
\text { estilo da arquitetura jesuítica na América. }\end{array}$ \\
\hline Casa Elfrida Lobo & $\begin{array}{l}\text { Estilo eclético, construída entre o final do século XIX, } \\
\text { início do século XX. }\end{array}$ \\
\hline $\begin{array}{l}\text { Casa onde moraram Brasílio Itiberê e e } \\
\text { Monsenhor Celso }\end{array}$ & $\begin{array}{l}\text { Casa térrea em alvenaria de pedra, construção do século } \\
\text { XVIII, possuía uma extensão em forma de sobrado } \\
\text { comercial. }\end{array}$ \\
\hline $\begin{array}{l}\text { Casa situada à Praça Monsenhor } \\
\text { Celso 106 }\end{array}$ & $\begin{array}{l}\text { Sobrado em alvenaria de pedra, construção datada } \\
\text { provavelmente do século XVIII. }\end{array}$ \\
\hline Estação Ferroviária de Paranaguá & $\begin{array}{l}\text { Construída no século XIX, arquitetura de estilo eclético } \\
\text { com características neoclássicas. }\end{array}$ \\
\hline
\end{tabular}




\begin{tabular}{|l|l|}
\hline Fonte Velha & Construída em 1657, toda em pedra. \\
\hline $\begin{array}{l}\text { Fortaleza Nossa Senhora dos } \\
\text { Prazeres }\end{array}$ & $\begin{array}{l}\text { Construída em 1770, a fortaleza está situada em uma aba do } \\
\text { morro da Baleia, na Ilha do Mel. }\end{array}$ \\
\hline Igreja da Irmandade de São Benedito & Construída no século XVIII, em alvenaria de pedra. \\
\hline $\begin{array}{l}\text { Igreja da Ordem Terceira de São } \\
\text { Francisco das Chagas }\end{array}$ & $\begin{array}{l}\text { Construída no primeiro quartel do século XIX, possui o } \\
\text { estilo barroco. }\end{array}$ \\
\hline $\begin{array}{l}\text { Igreja Nossa Senhora do Santíssimo } \\
\text { (Matriz) }\end{array}$ & $\begin{array}{l}\text { Construída no século XVIII, a partir do estilo colonial } \\
\text { português. }\end{array}$ \\
\hline Ilha do Mel & $\begin{array}{l}\text { Tombada com o intuito de impedir o turismo predatório e } \\
\text { conservar os hábitos caboclos, bem como a vegetação } \\
\text { natural. }\end{array}$ \\
\hline $\begin{array}{l}\text { Instituto de Educação Dr. Caetano } \\
\text { Munhoz da Rocha }\end{array}$ & $\begin{array}{l}\text { Inaugurado em 1927, o prédio possui arquitetura } \\
\text { neoclássica. }\end{array}$ \\
\hline Jazigo da Família Correia & $\begin{array}{l}\text { Datada do século XIX, possui o busto do Dr. Leocádio } \\
\text { esculpido na Itália. }\end{array}$ \\
\hline $\begin{array}{l}\text { Prédio da Prefeitura Municipal - } \\
\text { antigo Palácio Visconde de Nácar }\end{array}$ & $\begin{array}{l}\text { Construída no século XIX provavelmente para ser a sede do } \\
\text { governo da Província. }\end{array}$ \\
\hline Serra do Mar em Paranaguá & Tombamento segue o intuito de conservação natural. \\
\hline Setor Histórico de Paranaguá & $\begin{array}{l}\text { Contempla os casarios construídos entre os séculos XVIII e } \\
\text { XIX, que estão à beira do Rio Itiberê. }\end{array}$ \\
\hline Artesanato sacro / Imagens &
\end{tabular}

FONTE: PARANÁ, Imóveis tombados pelo Patrimônio Histórico e Artístico do Paraná: Setor Histórico de Paranaguá, 1990.

Além do seu conjunto arquitetônico e de imaginárias, o traçado urbano de Paranaguá revela um encontro espaço-temporal peculiar, que remete ao que François Hartog (2006) explicita como uma expressão do verdadeiro ser do corpo social da cidade. De um lado, a cidade atual apresenta uma faceta moderna e articulada aos grandes fluxos globais contemporâneos através das atividades econômicas típicas dos portos. De outro lado, seu núcleo histórico e sua interface com as ilhas que compõem a baía de Paranaguá expressam seus arcaísmos, sua tradição pré-moderna.

Formalmente compõem o mesmo núcleo urbano (cidade histórica e porto), mas efetivamente expressam temporalidades distintas através da própria configuração espacial. As fotos 2 e 3 permitem vislumbrar este ponto de vista, a faceta dos "arcaísmos" preservados na paisagem urbana.

\footnotetext{
5 O chamado Centro Histórico de Paranaguá é composto por uma área poligonal que busca contemplar a grande área de concentração das edificações destinadas à preservação.

${ }^{6}$ Os termos 'artesanato sacro' e 'imagem' são registrados no Livro Tombo do Estado do Paraná em referência a diversos bens de natureza simbólica religiosa, especialmente esculturas.
} 


\section{Em Paranaguá o Potencial para o Turismo Cultural Refletido no Tempo e no Espaço}

O povoado que deu origem à cidade de Paranaguá remonta ao século XVI, e está vinculado à ocupação da Ilha da Cotinga por portugueses. Conforme Caneparo (1999, p. 116-118), ainda neste século, os fundadores deste povoado ficaram na ilha da Cotinga durante cerca de 25 anos. Em 1622, quando Gabriel de Lara chegou ao local, na qualidade de capitão-mór, encontrou a Cotinga em plena decadência e rusticamente foi estabelecido um novo povoado à margem do rio, próximo à baía (NASCIMENTO JUNIOR, 1981).

A missão do fundador oficial da vila de Paranaguá, Gabriel de Lara, era estabelecer uma base militar de defesa na costa ao sul de Cananéia. No entanto, muito provavelmente, Lara administrou um arraial de mineradores, cujas características não deveriam ser mais complexas que a de um acampamento de pessoas rudes e obstinadas na busca por metais. Segundo Nascimento Junior (1981), tanto na Cotinga, como no continente, até a primeira metade do século XVII havia completo descaso pela habitação.

A exploração de metais preciosos foi o objetivo primordial da exploração mercantilista do século XVI. Foi em função desta que ocorreu a ocupação de Paranaguá e Curitiba na segunda metade do século XVI. Conforme Liccardo et al. (2004, p. 43) foi em torno de 1570-1580 que os exploradores começaram a se deparar com o ouro de aluvião nas regiões da Serra do Mar, ao sul da Capitania de São Vicente.

Ainda, de acordo com Liccardo et al., em meados do século XVIII, no entanto, a região foi declarada livre da mineração nas catas e faisqueiras. Fato que naturalmente teria tornado desinteressante a permanência da população que havia aflorado para o litoral e fundado Paranaguá, tal como ocorreu em diversas outras regiões mineradoras no Brasil e no mundo. A não confirmação desta tendência, portanto, ratifica a tese de que Paranaguá não sofreu o completo esvaziamento demográfico em função do caráter estratégico que assumiu ao longo do século XVIII.

Conforme Couto (2003) foi o posicionamento geográfico da vila na zona de conflito do domínio territorial entre Portugal e Espanha que a elevou à condição geoestratégica. "A decisão dos portugueses de se fixar nas terras ao sul foi uma conseqüência direta do conflito hispano-português na região do rio da Prata, que irrompeu novamente em 1723" (MAURO, 2004, p. 473). 
O período em questão coincidiu com o reinado de Dom José I, entre 1750-1777, vulgarmente compreendido como o período pombalino (MAURO, 2004). Neste, a geopolítica ascendeu a uma nova posição nas ações imperiais de Portugal (COUTO, 2003). Como havia sido afirmado anteriormente, o Brasil assumiu um papel central para o Império, especialmente em função do ciclo do ouro na região de Minas Gerais, Goiás e Mato Grosso. Neste sentido, tornaram-se elementos importantes da política territorial ${ }^{7}$ a delimitação das fronteiras, em especial no que se refere à posse dos territórios sulamericanos (COUTO, 2003, p. 53).

A partir desta perspectiva de defesa e delimitação das fronteiras, dois elementos ascenderam em termos de relevância estratégica, ambos sendo beneficiadores de Paranaguá. $O$ primeiro deles se refere à transferência da capital para o Rio de Janeiro $(1775 / 1780)$, o que reduziu substancialmente a distância entre esta e a fronteira sul $^{8}$. O segundo está relacionado à política de redução dos vazios demográficos no Brasil colonial. Segundo Couto (2003, p. 54-55), a baixa densidade demográfica foi considerada perigosa, na medida em que tornava vulneráveis as fronteiras entre o Império lusitano e as áreas ocupadas por franceses, ingleses, holandeses, e, sobretudo, espanhóis.

Ainda conforme a pesquisa de Couto (2003), a provisão de 09 de agosto de 1747 passou a oferecer condições vantajosas aos açorianos e madeirenses que quisessem se fixar na colônia americana. Entre os incentivos aos casais provenientes das ilhas, que deveriam ocupar as zonas de fronteira, esteve o transporte, a doação de terras, de animais, bem como suprimentos para instalação de lavouras. Decorreu daí, um surto migratório de açorianos e madeirenses para Paranaguá, bem como para Ilha de Santa Catarina, até o Rio Grande de São Pedro (do $\mathrm{Sul}^{9}$ (COUTO, 2003, p. 55).

Embora tenha sido estimulado o fluxo migratório, ainda assim não foi suficiente para povoar a vasta área do litoral sul. Em função disto, a Secretaria de Estado dos Negócios Estrangeiros e da Guerra concluiu que a miscigenação deveria ser estimulada como política de povoamento

\footnotetext{
7 Observe-se aqui que está sendo levado em conta o conceito clássico de território, a partir da base epistemológica edificada por Ratzel, segundo a qual existe uma relação estreita entre solo e Estado. O enraizamento de comunidades que exploram as potencialidades do território constitui o elemento fundador do Estado (RAFFESTIN, 1993).

${ }^{8}$ Conforme Pesavento e Monteiro (2006, p. 5) a transferência da capital do Brasil colônia para o Rio de Janeiro expressa um processo de fortalecimento econômico da economia fluminense, que se combina ao caráter político deste deslocamento.

${ }^{9}$ Vale dizer, que o mesmo processo ocorreu na fronteira norte e extremo norte do Brasil.
} 
(COUTO, 2003). O que se tornou muito mais incisivo na fronteira sul, onde ocorria a disputa territorial com a Espanha. Neste sentido, foram incentivados os casamentos interraciais, entre homens brancos e mulheres indígenas, através da concessão de benefícios para os filhos destes casais. Da mesma forma, havia medidas para reduzir as animosidades, bem como para cessar o processo de escravização dos indígenas, fato mais delicado.

A cultura caiçara, resultante do encontro das culturas portuguesa e indígena, é fruto deste processo de miscigenação que foi instituído através de uma política de Estado. Em função das especificidades do processo de desenvolvimento capitalista brasileiro, em especial da forma espacialmente desigual, é possível identificar as marcas desta cultura presentes ainda hoje na cidade de Paranaguá.

De forma mais contundente estes traços culturais se refletem nas ilhas da baía de Paranaguá, em função do menor acesso à dinâmica urbana e de mercado. Refletindo, pois, parte do patrimônio imaterial herdado pela cidade.

No litoral, as tradições se encontram no cotidiano; em muitas localidades ainda se pratica o artesanato tradicional. Os potes de barro, os trançados, as pinturas com traços europeus e índios, podem ser encontrados em lugares recônditos das baías do litoral paranaense. Os "caiçaras" confeccionavam, até bem pouco tempo, as canoas de um pau só, com a árvore do guapuruvu, que, quase extinta, obriga a busca de outras soluções. O fandango, bailado tradicional do litoral, possui um aparato impressionante que envolve as comunidades em todo o seu processo. As violas, as rabecas, os tamancos são feitos pela comunidade; as danças, os cantos e modo de executar os instrumentos e bailar as modas são transmitidos espontaneamente; o fandango de um lugar traz sua marca, sua identidade própria, diferenciandose de outros. É um arcabouço pertencente a uma comunidade, que identifica suas tradições, mentalidade e valores (PARANÁ, 2009).

De acordo com o levantamento conduzido desde 2007 no município foram identificados 120 bens culturais dos quais o IPHAN selecionou 27 para o trabalho de inventário e documentação (FUMTUR, 2009). Na mesma fonte consta que entre os bens documentados estão festas como a de Nossa Senhora do Rocio e de Nossa Senhora do Rosário, Boi de Mamão e a Lenda da Caveirinha, entre outros. Também menciona que foram incluídas manifestações como o Carnaval, a presença árabe na cidade e as colônias, que receberam imigrantes de diversos países. Como ressalva discorre-se que permanece, no entanto, a 
direção estadual de priorizar o registro do fandango caiçara como patrimônio cultural do Brasil.

\section{Ilha do Mel: patrimônio e história de Paranaguá}

Conforme o historiador Antônio Vieira dos Santos (1962), o povoado de Paranaguá ascendeu e foi organizado, a partir do ordenamento administrativo viabilizado pelos atos políticos executados ao longo do século XVIII. Segundo o autor consta dos relatórios do Ouvidor Pardinho que até 1721 imperava a total anarquia administrativa e judicial na vila. Tanto assim, que o ouvidor requeria providências contra devassas e apuração de crimes atrozes (SANTOS, 1962).

Ainda nesta mesma perspectiva de ordenamento esteve a construção da fortaleza da Ilha da Baleia, hoje conhecida como Ilha do Mel, cuja aprovação data de 1765 (NASCIMENTO JUNIOR, 1981). Visivelmente sua importância estratégica ficou subordinada à política de expansão de fronteiras definida no período pombalino, já que nas primeiras décadas do século XIX encontrava-se em pleno abandono.

Outra edificação que compõe o patrimônio material de Paranaguá, o antigo colégio dos Jesuítas, representa uma obra findada pouco antes das medidas pombalinas e que acabou sendo destituído das funções de escola jesuítica quando da expulsão desta ordem. Assim como o forte e o colégio Jesuíta, a imponência monumental de Paranaguá perdeu parte substancial de sua força com o fim do período pombalino (NASCIMENTO JUNIOR, 1929).

Apesar da mudança de conjuntura, o papel estratégico de Paranaguá ainda pôde ser observado em episódio marcante datado de 1850, envolvendo a pressão inglesa para o fim do tráfico de escravos para o Brasil. Conhecido como 'episódio Cormorant' envolveu um cruzador inglês que adentrou a baía de Paranaguá visando capturar três brigues: Sereia, Dona Atina, e galera Campeadora (WESTPHALEN, 1982).

A presença dos brigues na baía demonstrava o papel da região na recepção e fornecimento de escravos, à revelia das questões diplomáticas, que induziam o governo imperial a induzir o fim da escravidão (LEANDRO, 2003). Fato é que o episódio terminou com uma forte reação quando o cruzador inglês atravessou a barra da fortaleza da Ilha do Mel, causando assim a 
contenda diplomática. Alega-se que este episódio teria sido derradeiro para levar o governo brasileiro a assinar a lei Eusébio de Queiroz no mesmo ano de 1850 (SANTOS, 1962).

Em 16 de maio de 1972, por indicação do Instituto do Patrimônio Histórico e Artístico do Paraná, o governo do estado decretou o tombamento da Ilha do Mel, com o propósito de preservar-lhe a paisagem, a flora e a fauna, bem como conservar hábitos tradicionais de seus antigos habitantes e evitar a especulação imobiliária (PARANÁ, 1972).

Atualmente, a Ilha do Mel constitui o atrativo turístico 'consolidado' no litoral do Paraná ${ }^{10}$, tombada pelo estado do Paraná desde 1972. Contudo, o tombamento em 1975 (PARANÁ, 1985) de seu principal monumento histórico, representado pela Fortaleza, ocorreu depois de várias reformas que alteraram as características originais da mesma (LOSEKANN, 2009b). Em que pese à descaracterização, a Ilha representa uma síntese da diversidade cultural do lugar, combinando os elementos natural, monumental e cultural.

O desenvolvimento do turismo na Ilha do Mel aparece muito vinculado ao seu potencial natural, que se soma ao patrimônio histórico. A política de controle de acesso à ilha em respeito às suas vulnerabilidades físicas corroboraram para cercear um processo descontrolado de ocupação. Vale dizer, conforme Sperb e Teixeira (2006, p. 443) que nos anos 1990 ocorreu a mudança mais relevante no que afeta o ambiente turístico na ilha, quando o perfil dos moradores e dos visitantes passou a se vincular de forma mais contundente ao ambiente natural preservado e seu valor simbólico. Ocorreu, por assim dizer, um aumento do grau de profissionalização da Ilha, com a presença mais forte de estabelecimentos ligados ao turismo e a conseqüente redução das casas de veraneio.

As conjunturas política e econômica atuais, por sua vez, são favoráveis ao desenvolvimento turístico, possibilitando que seja ressaltada a diversidade e o potencial para o turismo cultural ao longo de toda a orla, sobretudo na cidade de Paranaguá, tendo em vista o patrimônio da cidade histórica ${ }^{11}$. De fato, a Ilha do Mel representa seu patrimônio nacionalmente

10 Esta característica foi determinante na definição da cidade de Paranaguá como destino indutor do desenvolvimento turístico no estado no Plano Nacional de Turismo - 2007/2010 (BRASIL, 2006).

11 Além das edificações tombadas pelo Patrimônio Histórico estadual e agora sob a chancela de patrimônio nacional, cuja composição envolve cerca de 16 edifícios e monumentos, foi dado início à realização do 
reconhecido, o que explica o fato de que no Plano Nacional de Turismo - PNT 2007-2010 (BRASIL, 2006), o destino indutor Paranaguá é seguido de Ilha do Mel. Há, portanto, uma porta aberta para que seja estruturado e consolidado um referencial mais amplo relacionado à cidade e através dela para os outros atrativos culturais do litoral paranaense.

\section{Paranaguá: de cidade portuária a destino indutor do desenvolvimento turístico}

A atividade portuária em Paranaguá não foi definida no século XIX, na verdade ela parece tão antiga quanto à própria cidade. $\mathrm{O}$ vilarejo perpetuado a partir do esgotamento do surto de exploração de ouro inseriu-se economicamente a partir da função portuária. $\mathrm{O}$ primeiro porto situou-se na ilha da Cotinga, como atracadouro, e às margens do rio Itiberê (GODOY, 1998).

Ainda, conforme Godoy (1998), em 1851, Paranaguá perdeu seu papel na organização política da região sul do Brasil. Ao ser criada a província do Paraná e estabelecida Curitiba como sua capital delineou-se o esvaziamento da primeira cidade. Foram o porto e a vida cultural já estabelecidos na cidade de Paranaguá que a sustentaram. Em 1880, a criação da estrada de Ferro Paranaguá-Curitiba selou o último arranjo político destacável da sua elite, destituindo o porto de Antonina, seu concorrente, do posicionamento estratégico (SCHEIFER, 2008). Esta mudança se associa à construção de uma nova estrutura portuária, o Porto D. Pedro II, inaugurado em 1935.

A atividade portuária assumiu desde o início uma posição de centralidade na economia e na definição da organização do espaço urbano de Paranaguá. Segundo Godoy (1998, p. 102), cidade e porto estavam intimamente vinculados no ordenamento espacial. O posicionamento do porto à beira do Rio Itiberê, em torno do qual se formou a Vila, bem como a concentração da realização dos negócios na rua principal (Rua General Carneiro, hoje rua do centro histórico) permitiram a Godoy concluir que não havia distinção espacial entre as atividades portuárias e as demais atividades da cidade. A abertura das novas instalações do Porto D. Pedro II, por sua vez, alterou a espacialidade do município, estabelecendo a separação entre porto e cidade. 
Contemporaneamente, em especial a partir da década de 1990, com a abertura comercial e o processo de modernização portuária no Brasil inaugurou-se uma etapa que vem tornando porto e cidade ainda mais afastados (VIEIRA e VIEIRA, 2000). A dinâmica portuária reflete os fluxos globais, de onde se impõe a redução dos custos logísticos, a automação crescente dos processos, economizando empregos e sofisticando as exigências relativas ao emprego de pessoas (GOULART FILHO, 2007). Neste sentido, a atividade portuária torna-se visivelmente insuficiente para promover o desenvolvimento da cidade que a abriga. Por outro lado, o início da atividade portuária à margem do Rio Itiberê deixou como legado seu mais expressivo patrimônio material constituído por atracadouro, casas de comércio e outras edificações. Ainda assim não se verifica qualquer iniciativa por parte da administração portuária no sentido de recuperar e investir neste patrimônio, como contrapartida para o desenvolvimento da cidade.

Assim, o patrimônio arquitetônico bem como o patrimônio imaterial relativamente preservado nas manifestações culturais e no modo de vida dos ilhéus apresenta-se como potenciais para o desenvolvimento da região. Consoante a esta perspectiva, o turismo cultural pode representar um caminho para recuperação da auto-estima da população, ao mesmo tempo em que o seu desenvolvimento requer que esta questão seja trabalhada por meio dos processos educacionais. O planejamento turístico, enquanto fenômeno contemporâneo representa papel essencial no sentido de articular o lugar e o mundo (LUCHIARI, 2004, p. 108).

Se por um lado representam a produção dos espaços para o consumo, por outro lado, representam as formas contemporâneas de espacialização social, por meio das quais estamos construindo novas formas de sociabilidade, mais híbridas e flexíveis.

Ávila e Wilke (2008) apontam para as fraquezas e forças presentes na cidade de Paranaguá no sentido de desenvolvimento do turismo de uma forma geral. De um lado, a infra-estrutura e equipamentos urbanos somados aos recursos histórico-culturais dão sustentação ao potencial para o desenvolvimento do turismo, hoje insuficientemente explorado na cidade. Por outro lado, os autores mencionam a sazonalidade e o freqüente descumprimento das leis de proteção do patrimônio, natural e cultural, como dificultadores do desenvolvimento turístico na cidade. 
É importante acrescentar que a cultura empreendedora da cidade ainda está distante daquela que se percebe em lugares que investem no turismo cultural e histórico.

A pesquisa realizada pelo Instituto Paranaense de Desenvolvimento Econômico e Social IPARDES em conjunto com a Secretaria Estadual de Turismo do Paraná - SETUR/PR (2008) sobre a dinâmica da cadeia produtiva do turismo no litoral do Paraná deixa evidenciado, em termos estatísticos, a superioridade de Paranaguá no que tange à infra-estrutura e aos equipamentos urbanos de suporte ao turismo. Contudo, também fica demonstrado que esta infra-estrutura está voltada para atender essencialmente à demanda gerada pela atividade portuária, estimulando a despreocupação dos empresários em relação às necessidades de adaptações do modelo de negócio para o atendimento de um público voltado para o turismo. Ainda assim, esta capacidade logística de oferta de serviços típicos da cadeia turística pode ser vista como potencialidade para o desenvolvimento de políticas de fomento ao desenvolvimento das atividades vinculadas ao turismo cultural.

O turismo, em particular o turismo cultural, não representa uma espécie de redenção da cidade, no que tange à dependência a que foi submetida em relação a uma atividade econômica altamente impactante do meio ambiente natural e social. Contudo, é portador de novas perspectivas econômicas e de organização social, que podem revalorizar elementos inerentes à cultura e trazer de volta o valor social perdido com o tempo, mas que as marcas espaciais insistiram em manter presentes.

Não se pode afirmar que o patrimônio cultural deva ser preservado e conservado para que o turismo possa utilizá-lo como elemento de atratividade, pois a questão é muito mais abrangente, mas não se pode descartar a sua utilização como recurso de grande potencial (BAHL, 2004, p. $51)$.

Pode-se afirmar que existem elementos substanciais que habilitam Paranaguá, enquanto cidade indutora do desenvolvimento turístico a partir do Plano Nacional de Turismo (BRASIL, 2006), a reposicionar-se no cenário estadual e nacional através de uma marca cultural. Assim, a pesquisa histórica e a revalorização de seu patrimônio material e imaterial consistem em subsídios para a definição de políticas públicas municipais que associem os benefícios das medidas estabelecidas nos níveis federal e estadual. 
O PNT 2007-2010, por sua vez, propõe-se ao alinhamento das políticas públicas relacionadas ao turismo com a proposição de desenvolvimento na perspectiva da inclusão social.

O sentido profundo deste Plano Nacional do Turismo 2007/2010 é a inclusão social. Trata-se de erguer pontes entre o povo brasileiro e as esferas de governo federal, estadual e municipal, bem como da iniciativa privada e do terceiro setor, para construir um lazer que seja também uma visão compartilhada da nossa terra, da nossa gente, da nossa imensa vitalidade econômica, cultural e ambiental (BRASIL. 2006, p. 5).

O corpo do texto da política nacional de turismo traz como princípios orientadores os conceitos de cooperação, integração, sustentabilidade ambiental, econômica, sociocultural e político-institucional. O que indica que tem como pano de fundo o propósito do desenvolvimento a partir de uma perspectiva que supera a lógica que iguala ao crescimento, geração de riqueza e renda, independentemente da forma de distribuição e da capacidade de criação de oportunidades para os moradores dos destinos turísticos.

O discurso do desenvolvimento absorve a noção de sustentabilidade como elo entre o presente da atividade e aquilo que deixa de herança para as gerações que o sucedem no tempo (SACHS, 2004). Neste sentido, o sucesso da atividade turística deixa de ser medido pelo número de visitantes, passando a ser mensurado pela receita gerada pelos turistas, pela qualidade dos turistas, bem como pelos benefícios sociais que advém das atividades a ele relacionadas.

A efetivação deste conjunto de proposições e de perspectivas, no entanto, depende essencialmente da capacidade de articulação destes propósitos gerais pelas instâncias que representam a municipalidade, executora e gestora do ambiente sobre o qual se erguem e realizam as atividades turísticas. Sem tomá-lo como uma panacéia, vale destacar que o planejamento é requisito básico para colocar em prática os princípios do desenvolvimento a partir das bases endógenas do lugar, de modo a ampliar a sua sustentabilidade (SACHS, 2004).

No caso de Paranaguá, como se buscou explicitar até aqui, através de seu patrimônio apresenta um atrativo relevante e efetivo. Desta forma, pode se espelhar em diversas cidades que vêm implementando políticas de valorização das suas espacialidades históricas, como é o 
caso de Buenos Aires, ou de Havana (ressalvada a especificidade do regime político). Em todos estes casos o planejamento turístico visa tornar atraente o centro velho ou cidade histórica.

A atratividade da cidade histórica, por sua vez, deve ser acompanhada de funcionalidade ${ }^{12}$, tanto para os visitantes, como para a população. Atualmente, não existe, supostamente em função da insuficiência de recursos, um conjunto de investimentos que redefinam as funções do centro histórico da cidade de Paranaguá. Além disso, há que se pensar na recuperação da auto-estima da população, combalida como conseqüência da perda progressiva de sua importância no cenário nacional e regional desde o século XIX (SCHEIFER, 2008).

\section{Apontamentos Finais}

Em termos de apontamentos finais, pode-se dizer que o caso de Paranaguá expressa uma confluência de fatores que elevam seu potencial cultural. Isto porque persistem em seu território traços efetivos da cultura tradicional caiçara, o que pode se traduzir em atratividade real, ao mesmo tempo em que a cidade convive com as demandas oriundas do fluxo global de comércio, típicas das áreas portuárias. Converter este potencial em atrativo requer sensibilidade, conhecimento profundo da história e da cultura local, bem como a disponibilidade de diálogo e de respeito às diferenças.

Vale dizer, para concluir, que ao longo do século XX, em especial a partir dos anos 1950, com o boom da exportação cafeeira, a cidade tornou-se receptora da migração de pessoas advindas do meio rural, em especial da área insular da baía (GODOY, 1998). A precária incorporação destes trabalhadores pobres na economia local e regional significou um processo intenso de periferização e aumento da violência, o que se relaciona diretamente à exclusão sócioespacial.

Conforme Pelegrine (2005, p. 51), a articulação entre turismo e comércio de serviços culturais a partir da colaboração entre administração pública e privada tem a característica intrínseca de oportunizar o desenvolvimento social. Para tanto, há que se pensar em políticas patrimoniais baseadas na perspectiva pluralista, que valoriza a diversidade cultural. Neste sentido, que

\footnotetext{
${ }^{12}$ A funcionalidade aqui se refere à dotação da cidade dos equipamentos tecnológicos disponíveis para gerar conforto e segurança, bem como mobilidade, tanto para os turistas, como para os moradores.
} 
também se possa perceber na cultura caiçara, por exemplo, não um empecilho ao progresso, mas um patrimônio que pode se transformar em atrativo, beneficiando à comunidade e não apenas aos empreendedores.

Sabe-se de antemão que a incorporação da idéia de desenvolvimento includente (SACHS, 2004) no âmbito do planejamento turístico parte de uma situação de alta complexidade social, bem como de vulnerabilidade explícita. O que significa que o ponto de partida do planejamento deverá contemplar soluções para questões relacionadas ao impacto sócioambiental da forma de ocupação da cidade.

Há que se buscar nas origens o que restou de todo um processo histórico de ocupação e de viver num determinado momento, assim, torna-se bastante evidente a necessidade de se preservar as edificações mais marcantes para o lugar, e que podem ter uma função cultural ou social servindo ao turismo como suporte e não apenas atendendo a interesses econômicos [...] (BAHL, 2004, p. 53).

Neste caso, o turismo pode também atuar como agente de difusão de uma localidade, exigindo para tanto, e até provocando, o resgate de valores e a sua necessidade de preservação. Sendo assim, acredita-se que o turismo cultural seja efetivamente uma das possibilidades para contrabalançar a excessiva dependência da atividade portuária a que está submetida a cidade. Ao mesmo tempo, abre campo para um conjunto de empreendimentos baseados na criatividade e no pluralismo.

\section{Referências}

ÁVILA, M. A.; WILKE, E. P. Dos fatores limitantes ao desenvolvimento sustentável: alternativas planejadas para o turismo em Paranaguá, Paraná, Brasil. In: Pasos - Revista de Turismo e Patrimônio Cultural, v. 6, n. 3, 2008.

BAHL, M. Legados étnicos \& oferta turística. Curitiba: Juruá, 2004.

BRASIL. Ministério do Turismo. Turismo cultural: orientações básicas. / Ministério do Turismo, Secretaria Nacional de Políticas de Turismo, Departamento de Estruturação, Articulação e Ordenamento Turístico, Coordenação Geral de Segmentação. - 2. ed. - Brasília: Ministério do Turismo, 2008. 60 p.; 24 cm. p. 16. Disponível em: <http://www.turismo.gov.br>. Acesso em: $08 / 10 / 2009$. 
. Ministério do Turismo. Plano Nacional de Turismo - 2007/2010 - Turismo uma Viagem de Inclusão. Brasília, Mtur, 2006.

CANEPARO, S. C. Manguezais de Paranaguá - Uma Análise da Dinâmica Espacial da Ocupação Antrópica - 1952-1996. Tese Doutorado (Pós-graduação em Meio Ambiente e Desenvolvimento). UFPR. Curitiba. 1999.

COUTO, J. O Brasil Pombalino. In: Revista Camões, n. 15/16, 2003. Disponível em: $<\mathrm{http} / /$ cvc.instituto-camoes.pt/conhecer/biblioteca-digital-camoes/cat view/62-revistas-e-periodicos/ 69-revista>. Acesso em: Março de 2009.

FITA, J. P. O Fórum universal das culturas: Barcelona de 2004. Políticas Culturais para o Desenvolvimento - Uma Base de dados para a cultura. Brasília: Edição da UNESCO no Brasil, Setembro de 2003.

FUNTUR. Fundação Municipal de Turismo de Paranaguá. Iphan realiza em Paranaguá inventário de referências culturais. 22/09/2009. Disponível em: <http://www.fumtur.com.br/noticias.php? noticia id=255>. Acesso em: Outubro de 2009.

GODOY, A. M. G. Um Olhar sobre a cidade de Paranaguá: Os impactos sócio-ambientais das mudanças portuárias. Tese de Doutorado. (Pós-graduação em Meio Ambiente e Desenvolvimento). UFPR. Curitiba. 1998.

GOULART FILHO, A. Melhoramentos, reaparelhamentos e modernização dos portos brasileiros: a longa e constante espera. Economia e Sociedade, v. 16, n. 3, Campinas, Dez/2007.

HARTOG, François. Tempo e Patrimônio. In: Varia História, Belo Horizonte, v. 22, n. 36: p. 261273, Jul./Dez. 2006.

INCUBADORA TECNOLÓGICA DE COOPERATIVAS POPULARES (UFPR LITORAL). Projeto Vila 2008. Matinhos, Universidade Federal do Paraná, 2008.

IPARDES / SETUR-PR - Instituto Paranaense de Desenvolvimento Econômico e Social / Secretaria Estadual de Turismo do Paraná. Cadeia produtiva do Turismo no Paraná - Estudo da Região Turística do Litoral, Curitiba, 2008.

LEANDRO, J. A. Gentes do Grande Mar Redondo: Riqueza e Pobreza na Comarca de Paranaguá. 1850 - 1888. Tese Doutorado (Pós-graduação em História). UFSC. Florianópolis. 2003.

LICCARDO, A.; SOBANSKI, A.; CHODUR, N. L. O Paraná na História da Mineração no Brasil do Século XVII. Boletim Paranaense de Geociências, n. 54, Curitiba: Editora Paranaense, p. 41-49, 2004.

LOSEKANN, S. Centro histórico de Paranaguá é tombado como patrimônio nacional. 03 de Dezembro de 2009a. Disponível em: <http://www.defender.org.br/centro-historico-de-paranagua-etombado-como-patrimonio-nacional/>. Acesso em: Março de 2010.

Fortaleza da Ilha do Mel terá condutores, vídeos e exposições. 15 de Janeiro de 2009b. Disponível em: <http://www.defender.org.br/Fortaleza-da-ilha-do-mel-tera-condutores-videos-eexposicoes/>. Acesso em: Abril de 2009.

LUCHIARI, M. T. D. P. Urbanização turística: um novo nexo entre o lugar e o mundo. In: SERRANO, C.; BRUHNS, H. T.; LUCHIARI, M. T. (orgs.). Olhares contemporâneos sobre o turismo. São Paulo: Papirus, 2004.

MARTINELLI, A. Cultura e Cidade: uma aliança para o desenvolvimento - A experiência da Espanha. In: Políticas Culturais para o Desenvolvimento - Uma Base de dados para a cultura. Brasília: Edição da UNESCO no Brasil, Setembro de 2003. 
MAURO, F. Portugal e o Brasil: A Estrutura Política e Econômica do Império, 1580-1750. In: BETHEL, L. (org.). História da América - Latina. América Latina Colonial. v. 1, 2. ed., 1 reimp., São Paulo, EDUSP, 2004.

MENESES, J. N. C. História e Turismo Cultural. Belo Horizonte: Autêntica, 2004.

NASCIMENTO JUNIOR, V. Os Jesuítas em Paranaguá. In: Revista O Itiberê. Arquivos do Instituto Histórico Geográfico de Paranaguá. Paranaguá. Anno XI, n. 127. Novembro de 1929.

Paranaguá. História, Crônicas e Lendas. Conselho Municipal de Curitiba. 1981. Disponível em: $\quad<$ http://patrimoniocultural.pr.gov.br/arquivos//benstombados/File/BIBLIOGRAFIA $\quad$ CPC/ ESPIRAIS/prg1.pdf $>$. Acesso em: Julho de 2009.

PARANÁ (Estado), Secretaria de Estado da Cultura e do Esporte; SPHAN/PRÓ MEMÓRIA. Fortaleza Nossa Senhora dos Prazeres. Curitiba, julho/1972. Disponível em: $<$ http://www.patrimoniocultural.pr.gov.br/modules/conteudo/conteudo.php?conteudo=188>. Acesso em: Maio de 2009.

Secretaria de Estado da Cultura e do Esporte; SPHAN/PRÓ MEMÓRIA. Fortaleza da Ilha do Mel. Curitiba, julho/1985.

Secretaria de Estado da Educação e da Cultura. Departamento do Patrimônio Histórico e Artístico. Imóveis tombados pelo Patrimônio Histórico e Artístico do Paraná: Setor Histórico de Paranaguá. Curitiba: SEEC/Imprensa Oficial Inscrição 109/II. Dez/1990.

. Secretaria de Estado da Cultura. Espirais do Tempo - Bens Tombados do Paraná. Curitiba, Paraná, Brasil. 2006.

. Secretaria de Estado da Cultura. Festas Populares - Inventário Cultural. Caderno 2, Curitiba, Paraná, Brasil, 2009.

Secretaria de Estado da Cultura. Livro Tombo Histórico. Curitiba, Coordenadoria de Patrimônio Cultural, Paraná, Brasil, 1990.

PELEGRINE, S. C. A. A propósito da Fruição e de Algumas Perspectivas Analíticas acerca do Patrimônio Cultural. In: Diálogos. Maringá: D. H. I. / PPh / UEM, v. 9, n. 1, p. 49-58, 2005.

PESAVENTO, F.; MONTEIRO, S. Jogos coloniais: mudança institucional e desempenho econômico, o caso da diversificação agrícola no Rio de Janeiro - 1750-1800. In: Anais do XXXIV Encontro Nacional de Economia (ANPEC). Salvador, 2006.

RAFFESTIN, C. Por uma geografia do poder. São Paulo: Ática, 1993.

SACHS, I. Desenvolvimento: includente, sustentável, sustentado. Rio de Janeiro: Garamond, 2004.

SAINT-HILAIRE, A. Viagem a Curitiba e Província de Santa Catarina. São Paulo, Ed. Villa Rica, 1978.

SANTOS, A. V. Memória Histórica Chronológica, Topográphica e Descriptiva da Cidade de Paranaguá e seu Municipio. Curitiba, Museu Paranaense, 1962.

SCHEIFER, B. Paranaguá, cidade Portuária: entre a cidade sonhada e a cidade real. Dissertação (Mestrado em História). UNIOESTE, Marechal Cândido Rondon, 2008.

SILVA, E. P. da. Patrimônio e Identidade. Os desafios do turismo cultural. ISCSP. Universidade Técnica de Lisboa, s/d. Disponível em: < www.aguaforte.com/antropologia/Peralta.html $>$. Acesso em: Janeiro de 2009. 
SPERB, Matias P.; TEIXEIRA, Rivanda M. A sustentabilidade ambiental do turismo na llha do Mel, Paraná: perspectivas dos gestores públicos. In: Turismo Visão e Ação, v. 8, n. 3, p.437-453, Set./Dez. de 2006.

TADEI NETO, P. Preservação sustentada de sítios históricos: a experiência do programa monumenta. In: Políticas Culturais para o Desenvolvimento - Uma Base de dados para a cultura. Brasília: Edição da UNESCO no Brasil, Setembro de 2003.

VIEIRA, M. M. F.; VIEIRA, E. F. Geoestratégia dos Espaços Econômicos: Transformação e Poder no Sítio Portuário e Retroportuário do Rio Grande - RS. Rio Grande. In: Organização \& Sociedade, v. 7, n. 19, Set./Dez. de 2000.

WESTPHAlEN, C. M. Comarca de Paranaguá no Comércio Marítimo do século XVIII. In: Revista do Instituto Histórico e Geográfico Brasileiro. Paranaguá, n. 336, Julho - Setembro de 1982.

Recebido em: 15/02/2010 (1 ${ }^{\mathrm{a}}$ versão) $31 / 08 / 2010$ ( $2^{\mathrm{a}}$ versão) $30 / 09 / 2010$ (3 ${ }^{\mathrm{a}}$ versão)

Aprovado em: 09/11/2010 